wondered if giving each bird species found in the Arctic was the best way of dealing with this group of birds. Some accounts are interesting, particularly those on waterfowl, which are the author's speciality; and on waders, such as knot, on which much research has recently been carried out. But some other sections are mere repetitions of textbook material. Chapters describing and comparing the characteristics of individuals of the group in the Arctic might have been far more readable and have provided an opporphotographs are useful additions to the text as is the up-to-date bibliography. The book is well producedrecommended for Arctic enthusiasts. tunity for more discussion. Maps and

Tony Soper's book Everyday Birds (David and Charles: Newton Abbot and London, £2.95) - a very popular account of the lives of nine very common birds-will please children and the less discriminating adult bird lover. Much of the text is very simple, factual and moves at a great pace, which is possibly why he makes the occasional careless statement such as "birds are controllers of insects" and "birds have a great sense of adventure". This book will be lapped up by a large market who will also enjoy Robert Gillmor's excellent drawings.

Peter Conder has recently retired as Director of the UK Royal Society for the Protection of Birds.

\section{Spirit of Nature needs rekindling}

OVER the past ten years, the study of animal social behaviour has undergone a dramatic change. Gone are the days when animals were held to do things 'for the good of the species' or for the benefit of their group if it meant that they themselves suffered in the process. Altruism -in the sense of behaviours which benefit the reproductive success of other unrelated individuals at the expense of an animal or its relativesis contrary to the Darwinian theory of natural selection. Selfishness and exploitation are the rule. So harsh a master is natural selection that it is not even the individual that benefits in the long run, but his genes. The individual animal has a finite lifetime, but his genes, in the bodies of his offspring, and in the offspring of his brothers and sisters or other relatives live on. Hence any genetic propensity to benefit relatives will be increased because the relatives will also be likely to have the same propensity. This idea of 'kin selection' has been fully developed by W. D. Hamilton.

In view of this shift of thought ('revolution' is too strong a word: it is more a realisation of what was implied all along by the theory of natural selection), it is disappointing to find that so many recent popular books still perpetuate the fallacy that the species is the unit of selection and seem unaware of recent developments in the field of evolutionary biology. This is particularly apparent in The Mating Game (Elsevier-Phaidon: Oxford, £4.50) by Robert Burton, a lavishly illustrated account of animal courtship and reproduction. The photography is most impressive, but the text is full of such statements as (p10) "the individual is unimportant and survives solely for the benefit of the whole", and (p8) "the function of sex is thus to ensure that animal populations are composed of a variety of individuals". The function of sex is one of the most hotly debated issues among evolutionists precisely because 'good of the population' arguments have been found to be inadequate. It may certainly be advantageous for the population as a whole to be variable, but the problem is that sexual reproduction involves producing individuals that contain only half the genes of each parent, an apparently enormous cost genetically, which asexually reproducing individuals would not have. The work of $R$. L. Trivers has made us take a new look at animal courtship and pair bonding. Animal family life is seen as a world of exploitation of one sex by the other, of cheating and of strategies involving cooperation only when this is selfishly the best thing to do. There is no mention of this aspect in the book, nor any of the genetic relationships between the members of a social insect colony, which is crucial to an understanding of their curious reproductive system.

Something of the same fallacy is apparent in John Napier's book Monkeys without Tails (BBC: London, f5.25), which on p33 states that "the whole life style of animals is a preparation for ensuring the continuity of their species" and that "animals that do not reproduce are biologically irrelevant". On the contrary, kin selection theory has shown that non-reproducing individuals may be genetically very important. This book, although a very interesting account of primate biology does not quite live up to its subtitleA Giraffe's-eye View of the Evolution and Life History of Man and the Chimpanzee. The idea is an appealing one-to look down on man from a great height as a rather ordinary primate-but the book is nevertheless rather noticeably anthropocentric. Man is placed at the top of the primate "staircase", with the "great divide" separating us from our primate relatives. There is a lot of useful information in this book, however, and it is very readable.

The Secret Life of Animals (Weidenfeld and Nicolson: London, £8.9.5) by Lorus and Margery Milne and Franklin Russell also insists that (p112) "whatever the behaviour is that best suits the survival of the species, occurs", but is redeemed by some really superb photography. The book really does succeed in conveying a sense of awe and wonder about animal Jife, which The Amazing World of Animals (Thomas Nelson: London, £4.50) edited and with a foreword by Sir Peter Scott also sets out to do. This book contains some good photographs, and chapters on different animal groups by various authors.

The Classification of Animals (White Lion: London, New York, Sidney and Toronto, £3.75) by R.ichard Freeman is a most useful illustrated summary of the classification of living animals, with examples, a clear indication of the numbers of species in each group covered, and a brief but informative description. It is concise, but at the same time satisfyingly comprehensive - the basic taxonomic information needed by a zoologist in a few pages.

The Language of Smell (Routledge and Kegan Paul: London and Boston, Massachusetts, £3.95), also by Robert Burton, is a summary of how animals smell and the uses to which they put their sense of smell, at a fairly elementary level. The recent evidence that shows that von Frisch has been right all along in claiming that the dances of honeybees transmit directional and distance information, is apparently unknown to the author. One is therefore, mistakenly given the impression that von Frisch is now generally considered to have been wrong and that bees rely on smell alone

It is a relief to turn to Bird Life: $A n$ Introduction to the World of Birds (Elsevier-Phaidon: Oxford, £5.95), with a text by Christopher Perrins. Here at least the basic evolutionary framework is sound and the current thought on social behaviour, mating, and so on, is simply and well explained. The book covers in a readable way various aspects of bird life, such as feeding, social hehaviour, migration and so on. It is clear, non-technical and has numerous coloured drawings by Ad Cameron, which although expert and lifelike, might perhaps be thought a little monotonous as the sole source of illustration.

Marian Dawkins

Marian Dawkins is a Departmental Demonstrator in Animal Behaviour in the Department of Zoology, University of Oxford, UK. 